\title{
UTILIZAÇÃO DO SISTEMA SODIS NA REGIÃO DE LONDRINA
}

\author{
V.B.DEGANUTTI ${ }^{1}$, L.F.LIMA ${ }^{1}$ e A.L.VIEIRA ${ }^{2}$ \\ ${ }^{1}$ Universidade Tecnológica Federal do Paraná, Departamento de Engenharia Ambiental \\ ${ }^{2}$ Universidade Tecnológica Federal do Paraná, Departamento de Tecnologia de Alimentos \\ E-mail para contato: lisandra@utfpr.edu.br
}

\begin{abstract}
RESUMO - O saneamento básico é de extrema importância para a saúde de uma população. O tratamento de água no Brasil é realizado em estações de tratamento (ETA), no entanto, a construção e manutenção destas ETA's possui alto custo, fazendo com que muitas cidades brasileiras não possuam condições financeiras para a sua construção ou mesmo o seu funcionamento para a integralidade da população. $\mathrm{O}$ objetivo deste trabalho foi o de analisar matematicamente a viabilidade de construir um módulo alternativo que sirva como forno solar e sistema de tratamento de água simultaneamente através da utilização da radiação solar local. Para que sua aplicabilidade seja efetiva é preciso avaliar a temperatura de centro do forno, pois para o sistema SODIS a temperatura mínima atingida deve ser $80^{\circ} \mathrm{C}$. O sistema proposto é construído com materiais reutilizáveis e de baixo custo, papelão, isopor, vidro e papel alumínio para que possa ser construído e utilizado por comunidades carentes. Resultados obtidos no balanço de energia do sistema mostraram a possibilidade de construção do forno a partir de materiais de baixo custo na região de Londrina em qualquer época do ano.
\end{abstract}

\section{INTRODUÇÃO}

A utilização de recursos energéticos renováveis é um dos temas de maior relevância nos dias atuais. A energia solar térmica é a forma de energia renovável mais facilmente disponível em nosso planeta e ainda subutilizada. ELETROBRAS (2004) trata a energia solar como uma fonte de energia alternativa promissora, favorecendo cada vez mais pesquisas para a sua utilização de forma efetiva.

Segundo a Organização Mundial de Saúde (OMS) cerca de 2 milhões de pessoas morrem em virtude de doenças originarias da ingestão de água contaminada,o uso desta para tomar banho ou lavar alimentos. No Brasil, aproximadamente 28 mil pessoas/ano ainda não tem acesso a água oriunda de estações de tratamento. Apesar de Londrina-PR estar em $10^{\circ}$ lugar no ranking brasileiro de saneamento básico, o índice de saneamento básico é de 83,8\%. Considerando a população de Londrina como 537566 habitantes, conforme estimativa do senso IBGE (2010) para 2013, mais de 80000 pessoas vivem sem água tratada na grande de Londrina. Esta população reside principalmente em área rural e em sua grande maioria é de baixa renda. 


\section{9 a 22 de outubro de 2014 \\ Florianópolis/SC}

O processo de desinfecção solar, também conhecido como SODIS (Solar Water Desinfection) é amplamente conhecido e bem utilizado em países em desenvolvimento e com alta incidência solar, como países do continente Africano e da América do Sul (SODIS, 2012). Este processo vem sendo estudado desde a década de 70 no Líbano e os resultados concluem que a exposição ao calor e as radiações ultravioletas, provenientes da radiação solar é um eficiente método de desinfecção com comprovada a capacidade de eliminação de patógenos (WEGELIN et $a l, 1994)$ e sem nenhuma alteração nas características químicas e sensoriais da água.

Conforme WEGELIN et al. (1994) a radiação UV-A do espectro violeta da luz visível tem caráter bactericida, sofrendo efeitos sazonais e de latitude local.

Um exemplo no qual pode demonstrar a eficiência do método, foi um estudo realizado por PIERIK (2010), no qual níveis satisfatórios de desinfecção para o consumo humano foram alcançados com a utilização de SODIS no verão em Toronto no Canadá. Dados como estes viabilizam a compreensão da possibilidade de utilização do SODIS para o Brasil, visto que a incidência solar, mesmo no inverno, apresenta valores mínimos de $200 \mathrm{Wm}^{-2}$ (MOURA, 2007), valor este muito superior ao encontrado no Canadá.

É importante enfatizar que o SODIS é agente da desinfecção microbiana, caso haja presença de outros contaminantes como e.x. metais pesados, produtos químicos na amostra de agua ao qual sofreu tratamento SODIS, estes resíduos não irão desaperecer, sendo necessário outros tratamentos adicionais para que a água se torne potável.

O publico alvo do processo SODIS são comunidades carentes, necessitando de alternativas de baixo custo para a confecção do sistema. Outras formas de desinfecção da agua incluem processos mais caros como: a fervura, que tem o custo da energia de aquecimento da água; a cloração, dificultada pela necessidade de controle de dosagem e do tempo de contato, e a filtração em vela cerâmica, requer um afluente com qualidade adequada para não entupir rapidamente o meio filtrante.

O processo SODIS original é a utilização direta de materiais PET reutilizáveis ou PVC para armazenamento da água e seu contato direto com o sol. A problemática deste método é que para dias de radiação menos intensa e velocidades do ar mais altas como inverno no sul do país, a temperatura de $80^{\circ} \mathrm{C}$ pode não ser atingida.

A proposta deste trabalho é a utilização de um forno solar, uma vez que este equipamento minimizaria as perdas de calor por convecção e auxiliaria na concentração solar superficial. Esta proposta propiciaria a utilização do sistema em qualquer estação do ano e ainda pode ser utilizado como forno solar.

Para captação e armazenamento de energia de forma satisfatória propõe-se a implementação de um concentrador solar, que no caso deste projeto será um forno solar no formato de caixa. Segundo MOURA (2007) o forno solar tipo caixa se apresenta como uma 
forma mais versátil do que o de formato parabólico, pois consegue captar energia suficiente para funcionar duas vezes por dia em uma ocasião de frio intenso.

O trabalho propõem a construção de um forno solar tipo caixa e o avalia quanto as dimensões necessárias para garantir que a temperatura no forno seja superior a $80^{\circ} \mathrm{C}$ em qualquer estação do ano para garantir sua aplicabilidade como forno solar de alimentos e sistema de desinfecção de água para comunidades carentes em Londrina-Pr. Para isto a construção do forno deve ser realizada de maneira simples com materiais reutilizáveis e de baixo custo para viabilizar a sua construção pela própria comunidade.

\section{METODOLOGIA}

O modulo experimental construído, conforme Figura 1, foi baseado no concentrador Solar do Instituto Mexicano de Tecnologia da Água. HERRERA (2003) desenvolveu um concentrador solar, de baixo custo, construído madeiras e recoberto com folhas de papel alumínio, para aumentar a eficiência do SODIS.

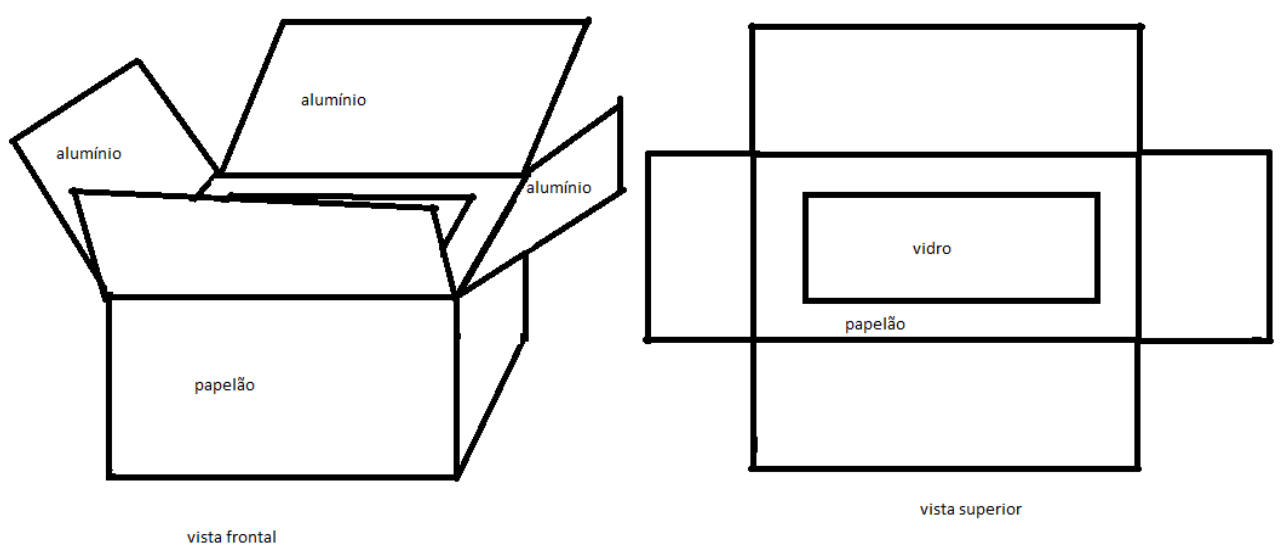

Figura 1 - Protótipo do forno solar desenvolvido

O forno foi construído por uma camada externa de papelão, camada intermediaria de isopor para minimizar as perdas de calor por convecção e camada interna de papel alumínio. A tampa foi constituída por papelão com uma abertura em vidro. Para auxiliar na reflexão do calor dentro do forno foram adicionadas abas revestidas de papel alumínio nos quatro lados da caixa para aumentar a área de captação de energia, facilitando a reflexão e transmissão da energia pelo vidro. As garrafas utilizadas para o armazenamento da água foram adquiridas com o reuso de vasilhames PET (politereftalato de etileno) descartados após o consumo de refrigerantes, sendo 
escolhidas as incolores, pois as cores marrom e verde absorvem radiação solar UV-A (WEGELIN et al., 2000).

O balanço energético e as perdas de calor por condução e convecção no forno foram realizados no software matemático MAPPLE-13. Assumiu-se convecção é natural em regime permanente e o sistema é unidimensional. Este balanço foi realizado através das parcelas de entrada e saída de energia, onde a energia que entra no forno é prioritariamente a energia por radiação e as perdas de calor acontecem por condução e convecção em cada uma das paredes.

Aproximações como as propriedades físicas e térmicas dos materiais constantes foram consideradas pela pequena faixa de variação de temperatura que acontecerá o processo. Os valores adotados para os cálculos seguem na Tabela 1

Tabela 1 - Propriedades físicas dos materiais utilizados na construção do forno

\begin{tabular}{cccc}
\hline Material & $\mathrm{k}(\mathrm{W} / \mathrm{mK})$ & $\alpha$ & $\varepsilon$ \\
& $\begin{array}{c}\text { Condutividade } \\
\text { Térmica }\end{array}$ & Absortividade & Emissividade \\
Isopor & $0,028^{* 1}$ & & \\
Papelão & $0,2^{* 3}$ & $0,67^{* 3}$ & $0,80^{* 3}$ \\
Papel & $160^{* 3}$ & $0,15^{* 2}$ & $0,05^{* 2}$ \\
Alumínio & & & $0,93^{* 3}$ \\
Vidro & $0,81^{* 3}$ & $0,034 \times 10^{-5 * 1}$ & \\
\hline
\end{tabular}

Fonte: *1- Fennelli, 2008; *2- Incropera, 1998, *3- Kreith, 2003

Para o calculo da energia obtida pela radiação, foram consideradas duas formas de obtenção dela: Primeiro a radiação que atinge diretamente o módulo (conforme Equação 1) e a outra a energia que é refletida pelas placas do concentrador solar (mostrada pela Equação 2). Para a obtenção de seus respectivos valores foram usadas as seguintes formulas:

$$
\begin{gathered}
E_{d}=I \cdot \tau_{v} A_{v} \\
E_{r}=0,8 \cdot I \cdot\left(\frac{A_{e}}{A_{v}}\right) \rho_{v} \tau_{v} A_{v}
\end{gathered}
$$

Onde:

$\mathrm{E}_{\mathrm{d}}$ : Energia que atinge diretamente o forno $(\mathrm{W})$ 
$\mathrm{E}_{\mathrm{r}}$ : Energia que atinge o forno por reflexão (W)

I:Incidência solar local $\left(\mathrm{W} / \mathrm{m}^{2}\right)$

$\tau_{\mathrm{v}}:$ transmissividade do vidro;

$A_{v}$ : área superficial do vidro $\left(\mathrm{m}^{2}\right)$;

$\mathrm{A}_{\mathrm{e}}$ área superficial das abas $\left(\mathrm{m}^{2}\right)$;

$\rho_{\mathrm{v}}$ : refletividade do papel alumínio

A energia na qual irá chegar até o módulo é a soma destas duas energias está representada pela Equação 3, e o balanço de energia global pode ser expresso pela Equação 4:

$$
\begin{aligned}
& E_{e}=E_{d}+E_{r} \\
& E_{e}-E_{s}=E_{a c}
\end{aligned}
$$

Onde:

Ee: é a energia incidente no modulo (J)

Es é a perda de energia pelos processos de convecção e condução (J)

Eac é a energia necessária para esquentar a água até $80^{\circ} \mathrm{C}(\mathrm{J})$

Com o resultado do balanço de energia final é possível modelar as extensões do módulo para que ele seja capaz de transferir calor a água suficientemente para que a mesma atinja temperaturas superiores a $80^{\circ} \mathrm{C}$ por pelo menos 4 horas.

Para o calculo da energia perdida por condução foram analisados os fluxos de uma forma horizontal, nas camadas laterais e frontais do módulo e vertical, na parte superior.

Para facilitar o calculo foram considerados como resistências cada nova parte aonde haveria a transmissão de energia, assim tem-se que o fluxo de energia para a condução das paredes laterais e para frente e fundo do módulo são respectivamente, conforme ilustração na Figura 2 


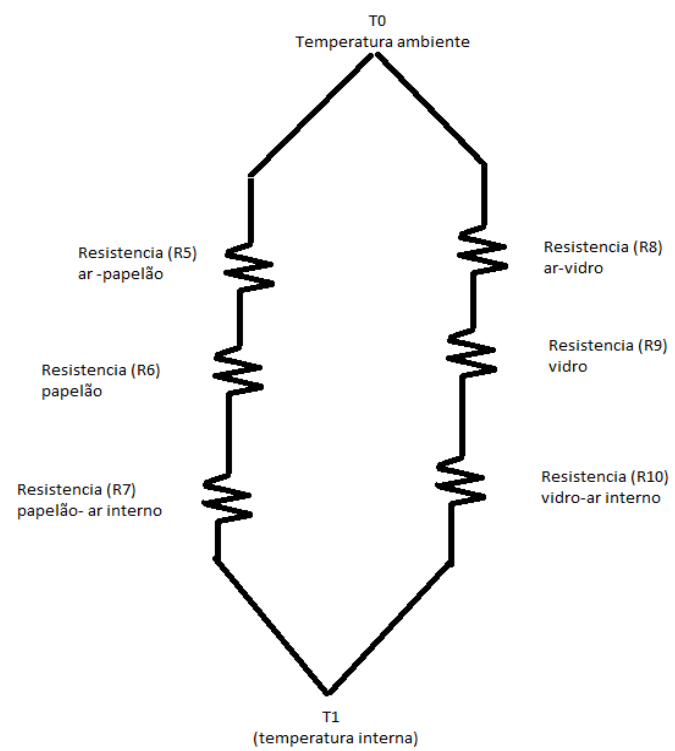

Figura 2 - Ilustração das resistências térmica na parte superior da caixa por condução

Os valores dos coeficientes de transferência de calor por convecção do ar-papelão; ar interno- papel alumínio; vidro- ar conforme o INCROPERA (1998).

\section{RESULTADOS}

Dados do SIMEPAR dos últimos anos para Londrina (2012 a 2014) apontam que a incidência solar em Londrina no período das 11:00 H as 14:00 H (5 horas de exposição) possui incidência solar entre $400 \mathrm{~W} / \mathrm{m}^{2}$ no inverno e $650 \mathrm{~W} / \mathrm{m}^{2}$ no verão.

Para a análise da viabilidade do módulo, foi considerado uma incidência solar média de $400 \mathrm{~W} / \mathrm{m}^{2}$ como a taxa de energia que entra no sistema, uma vez que este valor trata das condições mais desfavoráveis ao processo.

Para cálculos da quantidade de energia requerida pela agua para atingir a temperatura necessária, considerou-se a temperatura inicial da agua de $10^{\circ} \mathrm{C}$ e final de $80^{\circ} \mathrm{C}$, ou seja, uma variação de temperatura de $70^{\circ} \mathrm{C}$.

A energia final varia em relação a dimensão do forno solar, com isso também foi verificado quais seriam as dimensões ótimas para a construção do forno, sendo estas visualizadas no gráfico abaixo, conforme Figura 3.

O forno foi projetado em formato retangular para aumentar a área superficial do vidro. Considerou-se sistema permanente e unidimensional, e considerou-se que a parede do forno consistia de três camadas: papelão na parte externa, isopor, para minimizar as perdas energéticas e papel alumínio, para auxiliar na reflexão do calor dentro do forno. Existe ainda abas nos quatro 
lados da caixa para aumentar a área de captação de energia, vias radiação, facilitando a reflexão e transmissão da energia pelo vidro.

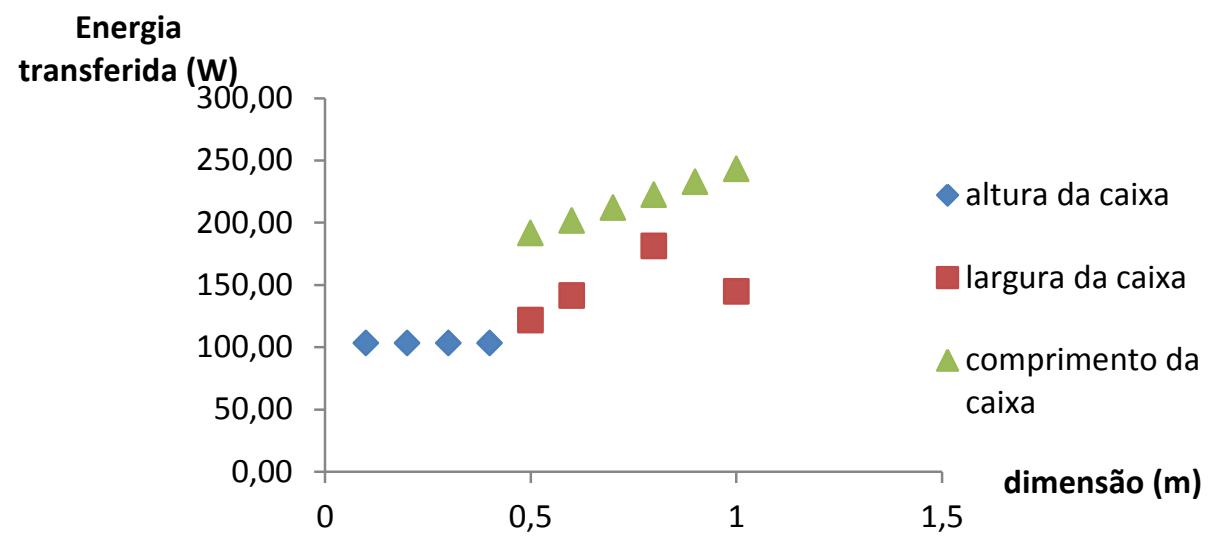

Figura 3- Energia transferida pelo sistema e dimensões do forno.

Para a modelagem das dimensões do módulo foi visto principalmente que quanto maior a largura do vidro e do módulo, maior será a energia obtida pelo módulo.

Assim no final da modelagem foi encontrado que a dimensão ideal para a montagem e funcionalidade do módulo foi do comprimento do vidro ser de 0,9 metros, a do módulo de 1 metro, a altura do módulo de 0,25 metros, a largura do módulo de 0,8 metros e a do vidro de 0,6 metros.

\section{CONCLUSÕES}

A utilização da energia solar para o tratamento de água é um ponto aonde existem poucas pesquisas relacionadas a ela, e a utilização de um sistema capaz de realizar este tratamento biológico, até mesmo no inverno, é um ponto importante para ser observado.

Analisando os resultados obtidos é possível observar que é possível a utilização do módulo para a região de Londrina, e também a construção deste com materiais propostos pelo artigo.

Além da possibilidade da construção, pelos resultados do balanço de energia o tratamento biológico será possível, assim com baixo custo, facilidade de construção e eficiência no tratamento, o módulo poderá ser usado para o seu objetivo. 
Os resultados obtidos no balanço de energia do sistema mostram a viabilidade do forno solar para a região de Londrina em qualquer época do ano e também a possibilidade de construção do forno a partir de materiais de baixo custo.

\section{REFERÊNCIAS}

ELETROBRAS; Energia Solar: Princípios e Aplicações, Centro de Referência para Energia Solar e Eólica Sérgio de Salvo Brito - CRESESB; 2004, 28p.

FENILLI, R.J. Sistemas termoisolantes: tipos, finalidade e aplicações. Revista de climatização $e$ Refrigeração. Editora Nova técnica, ISSN 1678-6866, Junho 2008, São Paulo, SP, 2008.

HERRERA, A. G. Desinfección Solar Del Agua, IMTA - Instituto Mexicano de Tecnologia del Água, Mexico, 2003.

IBGE, 2010- Censo demográfico de Londrina- PR- dados consultados no site http://cidades.ibge.gov.br/xtras/perfil.php?codmun=411370 dia 11/11/2013.

INCROPERA. F. P. e DEWITT, D. P., Fundamentos de Transferência de Calor e de Massa, ed. LTC, Rio de Janeiro, 1998.

KREITH, F., BOHN, M. S., Princípios de transferência de calor. $6^{\circ}$ edição, ed. Thomson, São Paulo, 2003.

MOURA, J. P. Construção e avaliação térmica de um fogão solar tipo caixa, UFRN Universidade Federal do Rio grande do Norte, Natal, 2007.

PIERIK, B. Investigations Concerning Solar water disinfection, Univesidade de Toronto, 2010.

SODIS, 2012, http://www.sodis.ch/index_EN, site acessado em 01/08/2012

WEGELIN, M.; CANONICA, S.; MECHSNER, K.; FLEISCHMANN, T.; PESARO, F.; METZLER, A., Solar water disinfection: Scope of the process and analysis of radiation experiments, Journal of Water Supply: Research and Technology - Aqua, 43(4), 154-169, 1994.

WEGELIN,M.; CANONICA,S.; ALDER, A. C.; MARAZUELA, D.; SUTER, M.J.F.; BUCHELI, Th. D.; HAEFliGER, O. P.; ZENOBI, R.; McGUIGAN, K. G.; KELLY, M. T.; IBRAHIM, P.; LARROQUE, M.; Does the Sunlight Change the Material and Content of Polyethylene Terephthalate (PET) Bottles?, Journal of Water Suply: Research and Technology Aqua, 2000.

\section{AGRADECIMENTOS}

Os autores agradecem a Fundação Araucária pelo apoio financeiro ao desenvolvimento deste trabalho. 